\title{
Endovascular treatment of duplicated inferior vena cava compression from retroperitoneal fibrosis
}

\author{
Cassius Iyad Ochoa Chaar, MD, MS, and Afsha Aurshina, MBBS, New Haven, Conn
}

\begin{abstract}
A 68-year-old man with a history of retroperitoneal fibrosis was referred to our clinic because of disabling bilateral lower extremity swelling and venous claudication, worse on the right side than on the left. He was noted to have a duplicated inferior vena cava and an iliac vein obliteration from retroperitoneal fibrosis. The patient underwent bilateral iliac vein stenting and had complete relief of symptoms through follow-up of 46 months with no recurrence. (J Vasc Surg Cases and Innovative Techniques 2018:4:311-4.)
\end{abstract}

Keywords: Inferior vena cava duplication; Retroperitoneal fibrosis; Venous compression

Retroperitoneal fibrosis (RPF) is a rare disease with a low incidence of 1 in 100,000. ${ }^{1}$ It is characterized by the presence of inflammatory and fibrous retroperitoneal tissue that often encases the ureters, abdominal aorta, and inferior vena cava (IVC), resulting in entrapment and obstruction of retroperitoneal structures. Although the mainstay of treatment involves oral administration of steroids and surgical ureterolysis, the treatment strategy for venous compression is not clearly defined. ${ }^{2,3}$ In this report, we describe a patient with disabling lower extremity swelling related to compression of a duplicated IVC from idiopathic RPF treated successfully with endovascular stenting. The patient's consent has been obtained for the study for inclusion of case details and imaging.

\section{CASE REPORT}

A 68-year-old African-American man was referred to our office by his primary care physician for evaluation of leg swelling, worse on the right side than on the left, that had worsened during a period of 2 months. The swelling and heaviness were most severe at the end of the day and interfering with his walking. He had used compression stockings with minimal relief.

His past history was significant for RPF treated in the past with steroids and mild renal insufficiency. He also had a previous

From the Section of Vascular Surgery, Department of Surgery, Yale University School of Medicine.

Author conflict of interest: none.

Presented at the Thirtieth Annual Meeting of the American Venous Forum, Tucson, Ariz, February 20-23, 2018.

Correspondence: Cassius lyad Ochoa Chaar, MD, MS, Section of Vascular Surgery, Department of Surgery, Yale University School of Medicine, 333 Cedar St, Boardman 204, New Haven, CT 06520-8039 (e-mail: cassius.chaar@yale. edu).

The editors and reviewers of this article have no relevant financial relationships to disclose per the Journal policy that requires reviewers to decline review of any manuscript for which they may have a conflict of interest.

2468-4287

(c) 2018 The Authors. Published by Elsevier Inc. on behalf of Society for Vascular Surgery. This is an open access article under the CC BY-NC-ND license (http:// creativecommons.org/licenses/by-nc-nd/4.0/).

https://doi.org/10.1016/j.jvscit.2018.07.002

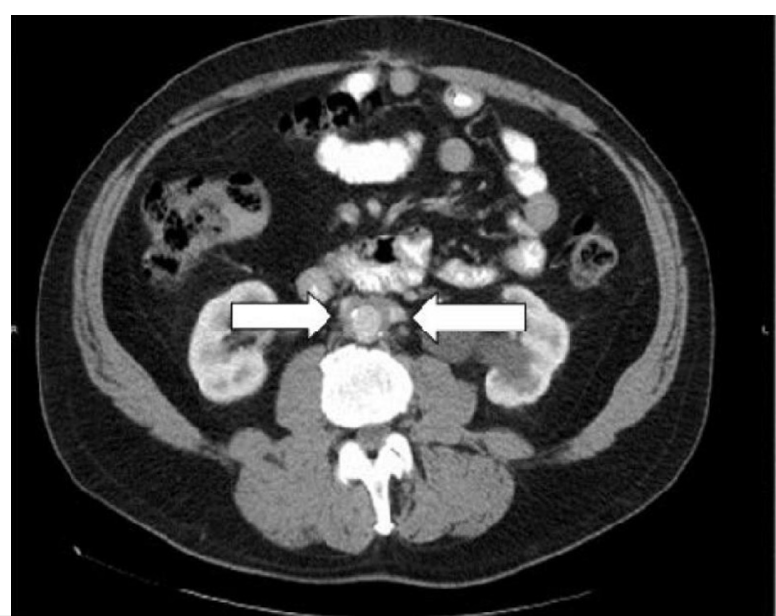

Fig 1. Computed tomography images showing initial preoperative retroperitoneal fibrosis (RPF), with fibrosis involving the duplicated inferior vena cava (IVC). The arrows point to the compressed duplicated vena cava on either side of the aorta.

history of retroperitoneal exploration, ureterolysis, and left hydrocele repair. He denied history of deep venous thrombosis. On physical examination, there was bilateral severe leg edema, worse on the right side, but no visible varicosities or ulcers. His arterial examination findings were normal. Duplex ultrasound imaging showed no evidence of deep venous thrombosis or venous reflux, but there was blunting of respiratory variation at the iliac veins. Review of a prior computed tomography scan performed after decompressive surgery for RPF showed the stenosed duplicated IVC and completely obliterated iliac veins (Fig 1).

The patient was taken for venography. Ultrasound-guided access of the bilateral common femoral veins was obtained with 6F sheaths. Pelvic venography was performed and demonstrated areas of severe focal stenosis (90\% bilateral; Fig 2, $A$ and $B$ ). Intravascular ultrasound confirmed the locations of stenosis as well as duplication of the IVC and was used for sizing the veins. A 16- $\times 60-\mathrm{mm}$ Wallstent (Boston 

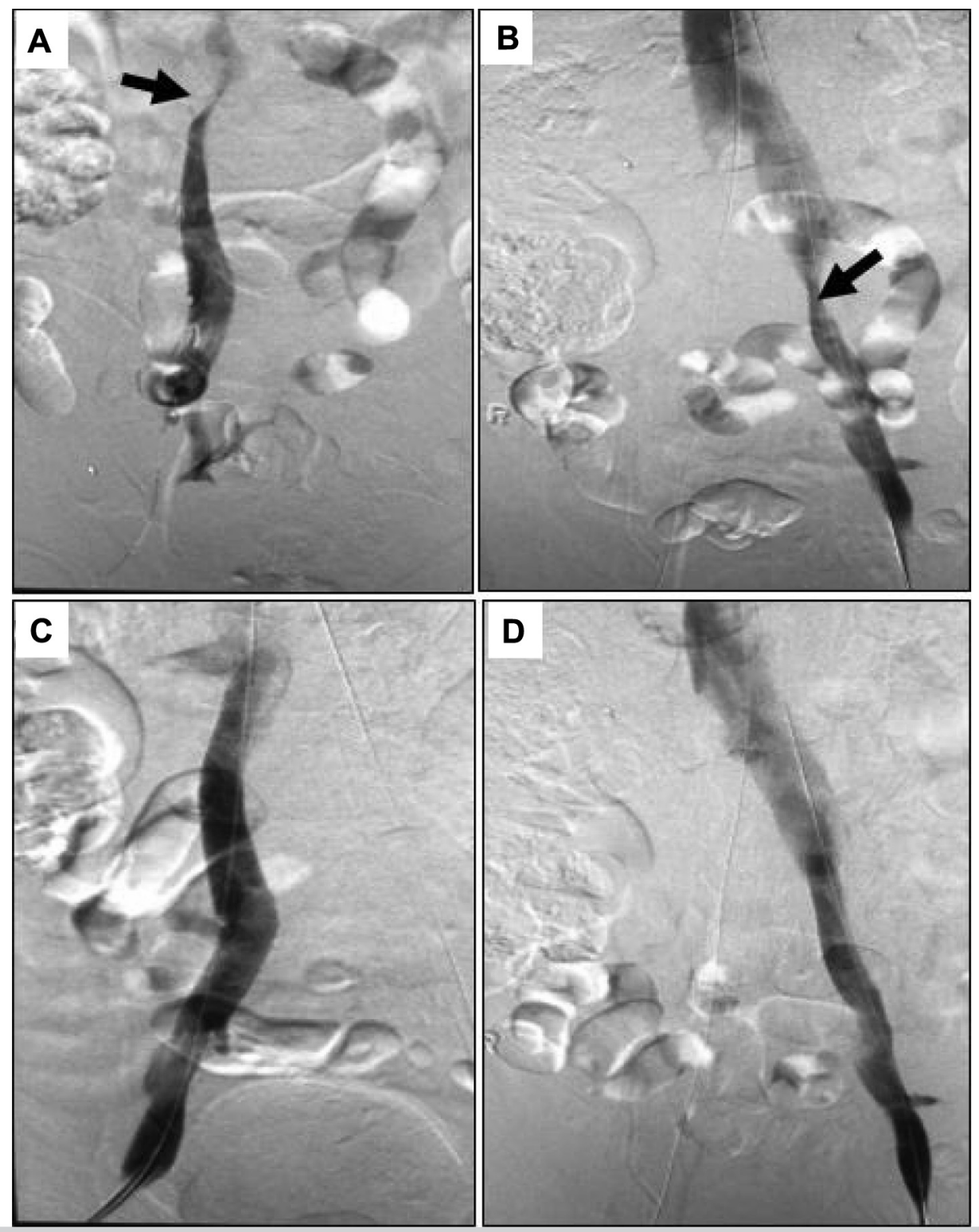

Fig 2. Pelvic venography. A and $\mathbf{B}$, Stenosis and filling delay in left common iliac vein and right external iliac vein, respectively (arrows). C and D, Postprocedural improvement after stent implantation.

Scientific, Marlborough, Mass) in the right external iliac vein and another 16- $\times$ 90-mm stent in the right-sided cava were deployed and postdilated with a 16- $\mathrm{mm}$ balloon (Fig 2, C). Next, two 14- $\times$ 60-mm stents were deployed with overlap on the left side and postdilated with a 14- $\mathrm{mm}$ balloon (Fig 2, D). At the end of the procedure, intravascular ultrasound was performed and confirmed no significant residual stenosis.

The patient was observed for 24 hours and had moderate pain after the procedure. His symptoms improved significantly within a week of treatment. The edema resolved on follow-up, and he currently uses stockings only infrequently as needed. He was prescribed clopidogrel $75 \mathrm{mg}$ daily for a year and then switched to aspirin. Computed tomography performed 3 years after the procedure showed patent stents with no stenosis
(Fig 3). He continues to be asymptomatic, and his duplex ultrasound examination showed patency of all stents 4 years after the procedure.

\section{DISCUSSION}

RPF, first described by Ormond in 1948, is an uncommon disorder that leads to fibrosis and compression of the structures in the retroperitoneum. ${ }^{1}$ It is most commonly idiopathic and rarely causes compression of the iliac artery or vein, leading to intermittent claudication, leg edema, and thrombosis. ${ }^{4}$ Symptomatic venous obstruction has been reported rarely, occurring in $2 \%$ of the cases. ${ }^{5}$ Koep and Zuidema ${ }^{6}$ reported that only $2.4 \%$ of their 491 cases with RPF had complications with iliac artery or vein stenosis. 


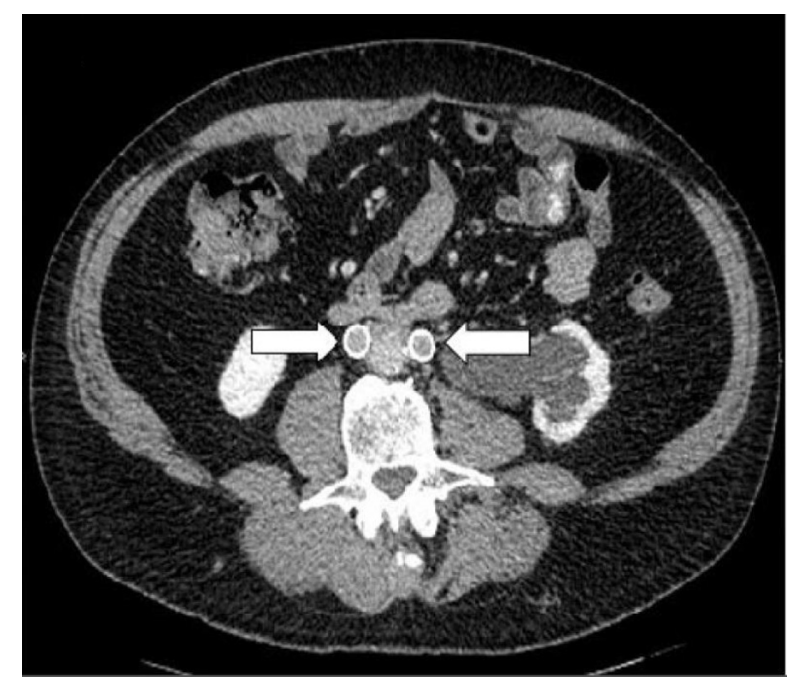

Fig 3. Postoperative computed tomography images showing patency of stents at 4 years of follow-up (arrows).

Compression stockings and steroids or immunosuppressive therapy are the basis for the medical treatment of RPF involving the iliac veins. Ilie et $\mathrm{al}^{7}$ reported that oral administration of prednisolone at a dose of $40 \mathrm{mg} / \mathrm{d}$ for a month showed regression of proliferated retroperitoneal tissue. Although the effect of implantation of a urinary tract stent to restrain progression of renal dysfunction has been recognized, the role of venous stenting to relieve vein compression from proliferated fibrosis remains unclear.

Previously, surgery for iliac vein involvement was performed with either direct (femoral or iliocaval bypass) or extra-anatomic (Palma procedure) reconstruction. ${ }^{8}$ In a study by Rhee et al, ${ }^{5}$ among the 17 cases of symptomatic iliocaval obstruction from RPF, medical treatment alone was provided to 7 patients. Surgery with venous bypass was performed in four patients and had good midterm results. On the other hand, all four patients treated with venous thrombectomy developed early thrombosis, none with an associated endovascular procedure. Endovascular technology has emerged as an alternative minimally invasive, effective treatment of iliac vein stenosis and thrombosis in the setting of RPF. $^{9-11}$

Hartung et $\mathrm{al}^{8}$ reported on two cases with RPF that were stented and had excellent clinical and angiographic long-term results with patency after 51 months and 36 months after the procedure, respectively. Only one case of complication after endovascular bilateral stent insertion has been reported to date by Vorwerk et $\mathrm{al}^{12}{ }^{12}$ with an acute right iliac deep venous thrombosis occurring 2 days after stenting. A percutaneous thrombectomy was performed, and iliac patency was re-established with bilateral stent insertion. In reports by Okuyama et $\mathrm{al}^{13}$ and Aissa et al, ${ }^{14}$ immediate
Table. Summary of literature review relating to endovascular management of iliocaval obstruction due to retroperitoneal fibrosis (RPF)

\begin{tabular}{|c|c|c|c|}
\hline Author & Year & $\begin{array}{l}\text { No. of } \\
\text { patients }\end{array}$ & Case summary \\
\hline Vorwerk et al & 1996 & 1 & $\begin{array}{l}\text { Bilateral iliocaval stenosis } \\
\text { due to RPF treated } \\
\text { with stenting and } \\
\text { angioplasty, complicated } \\
\text { by subsequent } \\
\text { thrombosis; } \\
\text { hydrodynamic } \\
\text { thrombectomy } \\
\text { performed and iliac } \\
\text { vein patency stabilized } \\
\text { using bilateral stents }\end{array}$ \\
\hline Hartung et al & 2002 & 2 & $\begin{array}{l}\text { Two cases treated with } \\
\text { transluminal } \\
\text { angioplasty and } \\
\text { stenting, with patent } \\
\text { iliac veins } 36 \text { and } \\
51 \text { months, respectively, } \\
\text { after procedure }\end{array}$ \\
\hline Aissi et al & 2004 & 1 & $\begin{array}{l}\text { Endovascular balloon } \\
\text { angioplasty and } \\
\text { stenting performed } \\
\text { because of high } \\
\text { cardiovascular risk, with } \\
\text { clinical success at } \\
\text { follow-up, suggesting } \\
\text { its role in fragile } \\
\text { patients }\end{array}$ \\
\hline Okuyama et al & 2010 & 1 & $\begin{array}{l}\text { Percutaneous } \\
\text { transvenous stent } \\
\text { performed, with } \\
\text { patency maintained at } \\
1 \text { year }\end{array}$ \\
\hline
\end{tabular}

improvement in the patient's leg edema and pain after stent implantation was observed, and the stent remained patent after 12 months (Table).

In this study, we reported a unique case of duplication of the IVC and bilateral venous compression due to RPF that improved after treatment with endovenous stent implantation. The stent has remained patent 46 months after the procedure.

\section{CONCLUSIONS}

lliocaval compression from RPF is rare but debilitating. Endovascular stenting of the iliac veins seems to be an effective and durable treatment.

\section{REFERENCES}

1. van Bommel EF, Jansen I, Hendriksz TR, Aarnoudse AL. Idiopathic retroperitoneal fibrosis: prospective evaluation of incidence and clinicoradiologic presentation. Medicine (Baltimore) 2009;88:193-201.

2. Gilkeson GS, Allen NB. Retroperitoneal fibrosis. A true connective tissue disease. Rheum Dis Clin North Am 1996;22: 23-38. 
3. Lepor H, Walsh PC. Idiopathic retroperitoneal fibrosis. J Urol 1979;122:1-6.

4. van Bommel EF. Retroperitoneal fibrosis. Neth J Med 2002;60:231-42.

5. Rhee RY, Gloviczki P, Luthra HS, Stanson AW, Bower TC, Cherry KJ Jr. Iliocaval complications of retroperitoneal fibrosis. Am J Surg 1994:168:179-83.

6. Koep L, Zuidema GD. The clinical significance of retroperitoneal fibrosis. Surgery 1977;81:250-7.

7. Ilie CP, Pemberton RJ, Tolley DA. Idiopathic retroperitoneal fibrosis: the case for nonsurgical treatment. BJU Int 2006;98: 137-40.

8. Hartung O, Alimi YS, Di Mauro P, Portier F, Juhan C. Endovascular treatment of iliocaval occlusion caused by retroperitoneal fibrosis: late results in two cases. J Vasc Surg 2002;36:849-52.

9. Hartung O, Otero A, Boufi M, De Caridi C, Barthelemy P, Juhan C, et al. Mid-term results of endovascular treatment for symptomatic chronic nonmalignant iliocaval venous occlusive disease. J Vasc Surg 2005:42:1138-44; discussion: 1144.
10. Juhan C, Hartung O, Alimi Y, Barthelemy P, Valerio N, Portier F. Treatment of nonmalignant obstructive iliocaval lesions by stent placement: mid-term results. Ann Vasc Surg 2001;15:227-32.

11. Neglen P, Raju S. Balloon dilation and stenting of chronic iliac vein obstruction: technical aspects and early clinical outcome. J Endovasc Ther 2000;7:79-91.

12. Vorwerk D, Guenther RW, Wendt G, Neuerburg J, Schurmann K. Iliocaval stenosis and iliac venous thrombosis in retroperitoneal fibrosis: percutaneous treatment by use of hydrodynamic thrombectomy and stenting. Cardiovasc Intervent Radiol 1996;19:40-2.

13. Okuyama H, Hirono O, Ishigaki D, Yuki K, Kubota I. Percutaneous transvenous stent implantation to external iliac vein stenosis in a patient with retroperitoneal fibrosis. Intern Med 2010:49:913-8.

14. Aissi K, Rossi P, Demoux AL, Hartung O, Frances Y. Endovascular treatment of iliocaval occlusion due to idiopathic retroperitoneal fibrosis. Eur J Intern Med 2004;15:534-6.

Submitted Apr 11, 2018; accepted Jul 7, 2018. 